\title{
Biological activity of dendritic cells generated from cord blood CD34+ hematopoietic progenitors in IL-7- and IL-13-conditioned cultures
}

\author{
Bożenna Mytar, Małgorzata Stec, Kazimierz Węglarczyk and Marek Zembala
}

Department of Clinical Immunology, Polish-American Institute of Pediatrics, Jagiellonian University Medical College, Cracow, Poland

Received: 2008.02.11, Accepted: 2008.12.19, Published online: 2009.02.14

(C) L. Hirszfeld Institute of Immunology and Experimental Therapy, Wrocław, Poland 2009

\begin{abstract}
Introduction: Dendritic cells (DCs) are required for initiation of the immune response and may therefore be used for the production of cancer vaccines. As mature DCs (mDCs) are the most potent antigen-presenting cells, there is increasing interest in generating them ex vivo. The present study was designed to obtain mDCs from $\mathrm{CD} 34^{+}$hematopoietic progenitors by culturing them in different media.

Materials and Methods: Cord blood CD $34^{+}$hematopoietic progenitors were expanded for 7 days in FST medium containing fms-related tyrosine kinase 3 ligand (Flt3-L), stem cell factor (SCF), and thrombopoietin (TPO). Then the cells were divided into three parts and cultured for 21 days in different media: FST medium or FST enriched in interleukin (IL)-3 (FST3 medium) or supplemented with IL-7 and IL-13 (FST713 medium). At the end of culture part of the cells was harvested, counted, and analyzed while the other part was matured with proinflammatory cytokines for 2 days. The cells' phenotypes, ability to induce proliferation of allogeneic lymphocytes in the mixed lymphocyte reaction (allo-MLR), chemotaxis, phagocytosis, and $\mathrm{O}_{2}^{-}$production were determined.

Results: The average fold increase of DCs at the end of culture in FST medium was 127, in FST3 1043, and in FST713 71. In comparison with the other media, FST713 medium supported the generation of mDCs that were characterized by higher expression of CD83, costimulatory molecules, and HLA-DR, enhanced ability to induce allo-MLR and migration to macrophage inflammatory protein (MIP) $3 \beta$, poor phagocytosis, and $\mathrm{O}_{2}^{-}$production.

Conclusions: This study indicates that FST713 medium allows the generation of limited numbers of more mature DCs, while FST3 medium leads to the production of immature DCs in high numbers.

Key words: allo-MLR, CD34+ cells, chemotaxis, dendritic cells, immunophenotype, phagocytosis.

Abbreviations: CCR - chemokine receptor, DCs - dendritic cells, FLT3-L - fms-related tyrosine kinase 3 ligand, FST - medium containing Flt3-L, SCF and TPO, FST3 - medium containing Flt3-L, SCF, TPO, and IL-3, FST713 - medium containing Flt3-L, SCF, TPO, IL-7, and IL-13, HE - hydroethidine, iDCs - immature DCs, IL - interleukin, mAb - monoclonal anti-

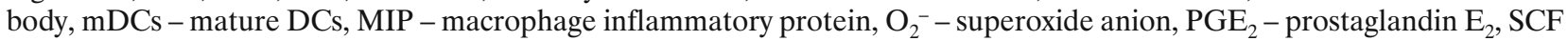
- stem cell factor, TNF - tumor necrosis factor $\alpha$, TPO - thrombopoietin

Corresponding author: Marek Zembala, Department of Clinical Immunology, Polish-American Institute of Pediatrics, Jagiellonian University Medical College, Wielicka 265, 30-663 Cracow, Poland, tel.: +48 12 658-24-86, fax: +48 12 658-17-56, e-mail: mizembal@cyf-kr.edu.pl
\end{abstract}

\section{INTRODUCTION}

Dendritic cells (DCs) are the most potent antigenpresenting cells and are required for the initiation of an immune response by stimulating naïve, memory, and effector T cells. They possess a wide spectrum of activity, ranging from induction of tolerance and prevention of autoimmunity to induction of antitumor response and protection against infectious agents (Banchereau and
Steinman 1998; Liu 2001). It is still an open question whether these activities are associated with separate subsets of DCs, their stage of maturation, or both (Liu 2001). There is growing interest in the development of methods which allow the generation of large numbers of DCs as they may be clinically useful in the production of cancer vaccines (Banchereau et al. 2001). Monocytes are the most commonly used source of DC precursors (Sallusto and Lanzavecchia 1994). Another possibility is 
to use $\mathrm{CD} 34^{+}$hematopoietic precursors from umbilical cord or peripheral blood which, in contrast to monocytes, proliferate in in vitro culture. Moreover, using various combinations of growth factors and cytokines it is possible to obtain DCs in different stages of maturation (immature: iDCs, mature: mDCs) and/or their different subsets (DC1, DC2) (Zou and Tam 2002).

A large variety of cytokines and conditions have been used for generating DCs which showed heterogeneity in phenotype and biological function. Medium containing fms-related tyrosine kinase 3 ligand (Flt3-L), stem cell factor (SCF), thrombopoietin (TPO), and interleukin (IL)-3 (FST3 medium) is one of commonly used for the expansion of DCs from CD34+ hematopoietic progenitor cells (Arrighi et al. 2003; Bontkes et al. 2002). When monocytes are used as a source of DCs, medium enriched with granulocyte-macrophage colony-stimulating factor (GM-CSF) and IL-4 is the most popular (Li et al. 2000; Romani et al. 1996; Zou and Tam 2002). In some experiments, IL-4 was replaced with IL-7 and it was shown that these DCs were more effective in enhancing anti-EBV T-cell cytotoxicity and proliferation of CD4 and CD8 T cells than DCs generated in GM-CSF and IL-4 (Takahashi et al. 1997). The surface markers exhibited by these cells were typical of those expressed by GM-CSF- and IL-4-derived DCs except that in contrast to the "classical" IL-4-derived DCs, IL-7-derived DCs showed CD14 expression (Li et al. 2000). When used with GM-CSF, IL-13, which shares many properties with IL-4 (Piemonti et al. 1995), promotes the differentiation of DCs from adherent peripheral blood mononuclear cells (Ahn and Agrawal 2005). Moreover, IL-13-generated DCs did not express CD14 molecules (Morse et al. 1999) and morphologically, phenotypically, and functionally were more mature than GM-CSF- and IL-4-induced DCs (Sato et al. 1999). These observations are in disagreement with other data which showed that IL-13 DCs are less differentiated than IL-4 DCs (Ahn and Agrawal 2005).

There are few studies concerning the effect of the above cytokines on the generation of DCs from cord blood CD34+ cells. Rosenzwajg et al. (Rosenzwajg et al. 1998) examined cord blood CD $34^{+}$cells cultured for the entire period in SCF, Flt3-L, GM-CSF, and TNF $\alpha$ medium with $10 \%$ FCS. After 5 days of culture, IL-4 or IL-13 was added, which allowed the generation of a large proportion of CD1a ${ }^{+}$DCs. Similar results were presented by Di Nicola et al. (Di Nicola et al. 1999) on $\mathrm{CD} 4^{+}$cells from mobilized peripheral blood. Against this background it was reasoned that the use of IL-7 and IL-13 jointly may result in the generation of more mature DCs without the requirement of their further differentiation with proinflammatory cytokines.

In the present study the phenotype and some biological activities of DCs originating from $\mathrm{CD}_{3} 4^{+}$hematopoietic progenitors cultured in FST medium (FST-DCs) or in FST3 (FST3-DCs) or FST713 (FST713DCs) media were determined. The $\mathrm{CD} 34^{+}$cells were first expanded in FST medium for 7 days, then divided and cultured in the three media for a further 21 days. We demonstrate that in comparison with the other media, FST713 medium supports the generation of mDCs characterized by higher levels of CD83, costimulatory molecules, and HLA-DR expression, an increased allostimulatory capacity and, following maturation, enhanced migration to MIP3 $\beta$ and increased expression of CCR7.

\section{MATERIALS AND METHODS}

\section{Isolation of $\mathrm{CD} 34^{+}$cells}

Human umbilical cord blood samples were obtained from normal full-term deliveries according to institutional guidelines. Mononuclear cells were isolated by standard Ficoll/Isopaque (Pharmacia, Uppsala, Sweden) density gradient centrifugation, incubated with bispecific anti-CD34 monoclonal antibody (mAb), anti-dextran tetrameric antibody complexes, and dextrancoated magnetic nanoparticles. The magnetically labeled cells were then separated in a magnetic field according to the manufacturer's protocol (EasySep; StemCell Technologies, Vancouver, Canada). The purity of the isolated cells was in the range of $89-95 \%$ as analyzed by flow cytometry (FACSCalibur, Becton Dickinson Immunocytometry System, San Jose, CA, USA) following staining with anti-CD34 mAb (Becton Dickinson, San Diego, CA, USA). The isolated CD34+ cells were suspended in Iscove's medium (Gibco, Paisley, UK) supplemented with $10 \%$ fetal bovine serum (Biochrom, Berlin, Germany), 2 mM L-glutamine (Gibco), $10 \mathrm{mM}$ hepes (Gibco), $2 \times 10^{-5} \mathrm{M} 2$-mercaptoethanol, and antibiotics (PNS; Gibco), further referred to as complete medium.

\section{Generation of dendritic cells}

For expansion, the $\mathrm{CD}_{3} 4^{+}$cells were cultured in complete medium enriched with $30 \mathrm{ng} / \mathrm{ml}$ recombinant human (rh) Flt3-L (specific activity: $1 \times 10^{6} \mathrm{U} / \mathrm{mg}$; CytoLab, Rehovot, Israel), $30 \mathrm{ng} / \mathrm{ml} \mathrm{rhSCF}$ (specific activity: $5 \times 10^{5} \mathrm{U} / \mathrm{mg}$; CytoLab), and $15 \mathrm{ng} / \mathrm{ml} \mathrm{rhTPO}$ (specific activity: $1 \times 10^{6} \mathrm{U} / \mathrm{mg}$; CytoLab) (FST medium) in ultra-low-attachment six-well plates (Corning Inc., New York, NY, USA) at $2-5 \times 10^{4} / \mathrm{ml}$. On the fourth day, half of the medium was replaced with fresh medium. After one week the cells were harvested, counted, and placed (at $5 \times 10^{4} / \mathrm{ml}$ ) in the following media: FST or FST further enriched in $30 \mathrm{ng} / \mathrm{ml}$ rhIL-3 (specific activity: $0.6-1 \times 10^{7} \mathrm{U} / \mathrm{mg}$; R\&D, Abington, UK) (FST3 medium) or $50 \mathrm{ng} / \mathrm{ml}$ rhIL-7 (specific activity: $2 \times 10^{6}$ $\mathrm{U} / \mathrm{mg}$; CytoLab) and $30 \mathrm{ng} / \mathrm{ml}$ rhIL-13 (specific activity: $1 \times 10^{6} \mathrm{U} / \mathrm{mg}$; CytoLab) (FST713 medium). The cells were incubated at $37^{\circ} \mathrm{C}$ in a $5 \% \mathrm{CO}_{2}$ atmosphere for a further 21 days, replacing the medium every fourth day. On day 21 the cells were collected for analysis of phenotype and biological activities. The remaining cells, seeded at $1-2 \times 10^{5} / \mathrm{ml}$, were used for maturation with 
a cocktail of proinflammatory cytokines containing rhIL-1 $\beta$ ((Sigma, St. Louis, MO, USA) at $2 \mathrm{ng} / \mathrm{ml}$, rhIL-6 (Sigma) at $10 \mathrm{ng} / \mathrm{ml}$, tumor necrosis factor $\alpha(\mathrm{TNF} \alpha$, a gift from Prof. W. Stec, Polish Academy of Science, Lodz, Poland; specific activity: $3 \times 10^{7} \mathrm{U} / \mathrm{ml}$ ) at $5 \mathrm{ng} / \mathrm{ml}$, and prostaglandin $\mathrm{E}_{2}\left(\mathrm{PGE}_{2} ;\right.$ Sigma $)$ at $1 \mu \mathrm{M}$ for a further 2 days and then harvested for analysis.

\section{Determination of immunophenotype}

The following fluorescein (FITC)- or phycoerythrin (PE)-conjugated mouse anti-human mAbs were used: anti-CD1a (clone HI149), -CD40 (clone 5C3), -CD83 (clone HB15e), -CD80 (clone L307.4), -CD86 (clone 2331), -CD33 (clone HIM3-4), -CD14 (clone MoP9), -HLA-DR (clone L243), -CD11c (clone B-ly6), -mannose receptor (MR, clone 19.2), -CD123 (clone 9F5), -CD16 (clone 3G8), and -CD45RA (clone HI100), all from BD Pharmingen, and anti-CD36 (clone FA6.152) from Immunotech (Marseille, France). For chemokine receptor analysis, anti-CCR5 (clone2D7/CCR5) mAb from BD Pharmingen and anti-CCR1 (clone 53504) and -CCR7 (clone 150503) from R\&D were used. Isotype controls included the appropriate FITC- or PE-labeled mouse $\operatorname{IgG}_{1}, \operatorname{IgG}_{2 \mathrm{a}}$, or $\mathrm{IgG}_{2 \mathrm{~b}}$. The cells were incubated with $\mathrm{mAbs}$ for $20 \mathrm{~min}$ at $4^{\circ} \mathrm{C}$, washed, resuspended in PBS, and analyzed by flow cytometry using CellQuest v.3.1 software.

\section{Mixed lymphocyte reactions (MLR)}

Peripheral blood mononuclear cells (PBMCs) isolated from EDTA-anticoagulated blood from healthy donors by standard Ficoll/Isopaque density gradient centrifugation were used as responding cells. Allogeneic PBMCs $\left(1.2 \times 10^{5} /\right.$ well $)$ were added to irradiated $(2500$ cGy) DCs $\left(1 \times 10^{2}\right.$ to $1 \times 10^{4} /$ well $)$ and cultured in RPMI 1640 medium (Gibco) with $10 \%$ pooled human $\mathrm{AB}$ serum for 6 days. One $\mu \mathrm{Ci} /$ well of $\left[{ }^{3} \mathrm{H}\right]$ thymidine (Amersham, Aylesbury, UK) was added for the final 18 $\mathrm{h}$ of culture, then the cells were harvested on a fiberglass filter and isotope uptake was determined in a $\beta$ scintillation counter (Beckman, Fullerton, CA). The results are expressed as mean counts per minute (cpm) of triplicates.

\section{Chemotaxis}

The chemotactic assay was performed on Costar Transwell 24-well plates with a $5-\mu \mathrm{m}$ pore-size filter (Costar Corning, Cambridge, MA). RPMI1640 medium supplemented with $0.5 \%$ bovine serum albumin alone or with macrophage inflammatory protein (MIP) $1 \alpha$ or $3 \beta$ (CytoLab, both at $100 \mathrm{ng} / \mathrm{ml}$ ) in a final volume of 650 $\mu \mathrm{l}$ was added to the lower chamber. The cells $\left(1 \times 10^{5} / 100 \mu \mathrm{l}\right)$ were placed in the upper chamber. As a control, $2 \times 10^{4}$ cells (i.e. $20 \%$ ) were put into the lower chamber. After $2 \mathrm{~h}$ the cells in the lower chamber of the Transwell were harvested and their number determined by flow cytometry. The cells were gated according to their FSC/SSC parameters and counted during a 20-sec acquisition time at a high flow rate. Data are expressed as the percentage of migrating cells according to formula: $\%$ of migrating cells $=$ number of cells in the test well $\times 20 \%$ /number of cells in the control well.

\section{Determination of phagocytosis and $\mathrm{O}_{2}^{-}$production}

DCs $\left(1 \times 10^{5} / 100 \mu \mathrm{l}\right)$ were thoroughly rinsed with RPMI 1640 medium without antibiotics and incubated for $30 \mathrm{~min}$ at $37^{\circ} \mathrm{C}$ in medium containing $10 \mu \mathrm{M}$ (final concentration) of hydroethidine (HE, Sigma). Then opsonized FITC-labeled S. aureus, prepared as previously described (Węglarczyk et al. 2004), was added at a bacteria-to-cell ratio of 20:1 and the cells were incubated for a further $30 \mathrm{~min}$ at $37^{\circ} \mathrm{C}$. Finally, $200 \mu \mathrm{l}$ of complete medium was added and the samples were analyzed by flow cytometry.

\section{Statistical analysis}

The non-parametric Mann-Whitney test was performed using GraphPad InStat version 2.0 software. $p$ values $<0.05$ were considered significant.

\section{RESULTS}

\section{Expansion of $\mathrm{CD} 34^{+}$hematopoietic progenitor cells and generation of $D C s$}

DCs were generated in two-step cultures. In the first step, isolated $\mathrm{CD} 34^{+}$cells were grown in FST medium for 7 days to expand hematopoietic progenitors. This represented the initial inoculum of cells, indicated hereafter as day 0 of culture, that were grown in different media. In the second step, the cells were transferred to FST, FST3, and FST713 media. Every week the cells were harvested and counted. The mean increase in total cell number during the first week of culture in FST medium was on average 12.6-fold. During the next 21 days the proliferation of cells was different in the FST, FST3, and FST713 media (Fig. 1). The mean fold increase in the total number of cells cultured in FST3 medium was 289, while in FST and FST713 only 42- and 6 -fold, respectively. From the beginning of $\mathrm{CD}^{2} 4^{+}$cell culture, i.e. during 28 days, the mean increase in the total number of cells cultured in FST was 127-, in FST3 medium 1043-, and in FST713 medium 71-fold.

\section{Surface markers expression}

Immunophenotypic analysis carried out on day 21 revealed different expressions of surface markers on the cells grown in the media used (Fig. 2). Almost all cells were $\mathrm{CD}_{3} 3^{+}$(not shown), indicating their myeloid origin. FST713-iDCs showed a significantly decreased proportion of $\mathrm{CD}_{14}{ }^{+}$cells and enhanced levels of $\mathrm{CD} 1 \mathrm{a}^{+}$, $\mathrm{CD} 40^{+}, \mathrm{CD} 80^{+}, \mathrm{CD}^{2} 3^{+}$, and HLA-DR ${ }^{+}$cells compared 


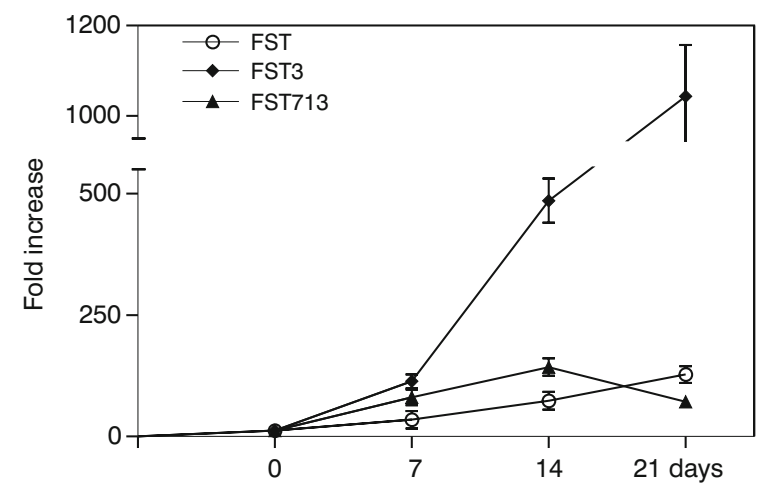

Fig. 1. Expansion of cord blood CD34+ progenitor cells. The cells were grown in FST medium for 7 days culture (indicated as day 0), then plated at $1 \times 10^{5} / \mathrm{ml}$ in FST, FST3, and FST713 media and cultured for a further 21 days. Every week the cells were harvested, counted, and split for further culture. The fold increase from the beginning of $\mathrm{CD} 34^{+}$cell cultures is indicated. On average, during the first 7 days cell yield was increased 12.6 fold. The highest total number of cells was obtained in cultures with FST3 medium. Mean \pm SEM of results obtained in five different experiments is shown.
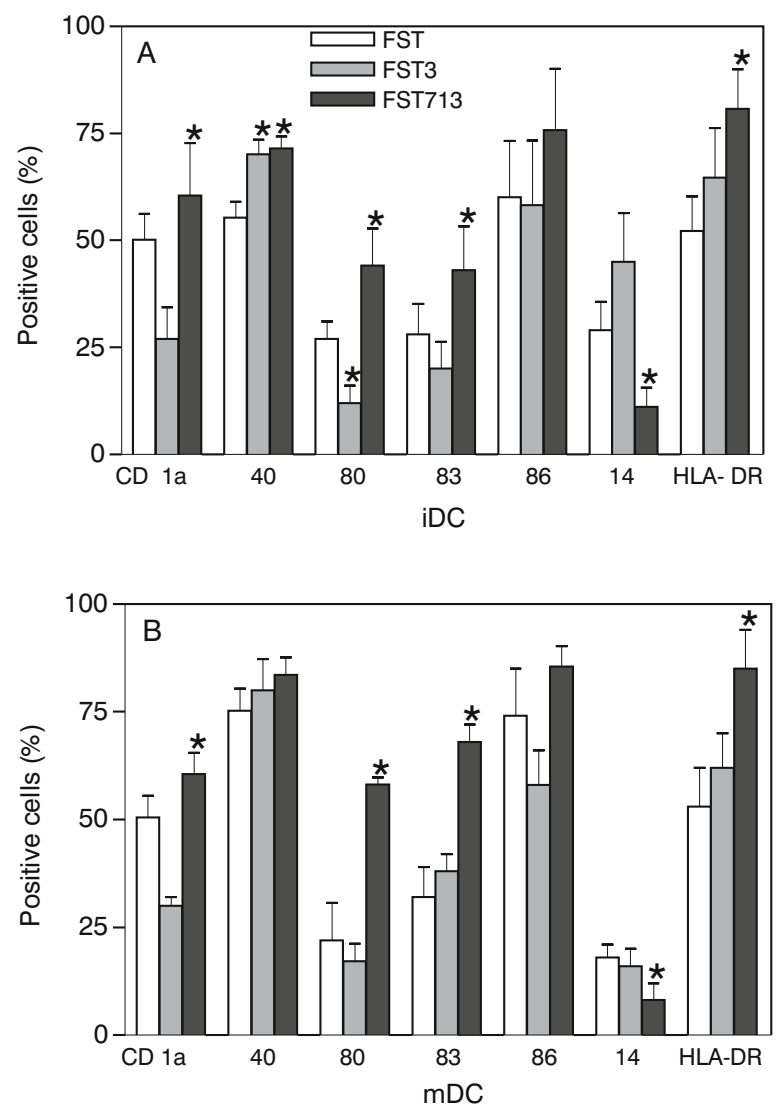

Fig. 2. The expression of surface determinants on iDCs (A) and mDCs (B). Cells were cultured in FST medium for 7 days and then cultured in different media for a further 21 days. Mean \pm SEM of results obtained in seven different experiments is shown. *Significantly different $(\mathrm{p}<0.05)$ from FST medium.

with FST-iDCs and FST3-iDCs (except for CD40 and HLA-DR in the latter). The level of $\mathrm{CD}^{+} 6^{+}$cells was also increased, although not significantly. Compared with FST-iDCs and FST713-iDCs, cells from FST3 medium showed lower expressions of CD1a, CD80, and CD83 and an elevated proportion of $\mathrm{CD}_{14}{ }^{+}$(Fig. 2A). There were no differences in CD36, CD11c, MR, and CD123 expression (not shown). Maturation did not significantly alter the expression of surface determinants on FST713-DCs, except for some elevation of CD40 ${ }^{+}$ cells. FST-DCs showed some increase in the numbers of $\mathrm{CD} 40^{+}$and $\mathrm{CD} 86^{+}$cells. In the case of FST3 medium, increase in $\mathrm{CD}^{+} 0^{+}$and $\mathrm{CD} 83^{+}$and a decrease in $\mathrm{CD} 14^{+}$ cells were observed (Fig. 2B).

\section{Stimulation of allogeneic MLR}

The allo-MLR stimulatory capacity of DCs expanded and matured in the different media was compared. iDCs generated in FST and FST3 medium were poor stimulators (Fig. 3). In contrast, FST713-iDCs exhibited significantly enhanced stimulatory capacity. Following maturation for a further 2-3 days, enhanced allostimulatory capacity of cells cultured in all the media was observed, but FST713-mDCs were still the most potent stimulators. It was concluded that the use of FST713 medium was superior for generating mDCs with increased allostimulatory capacity.
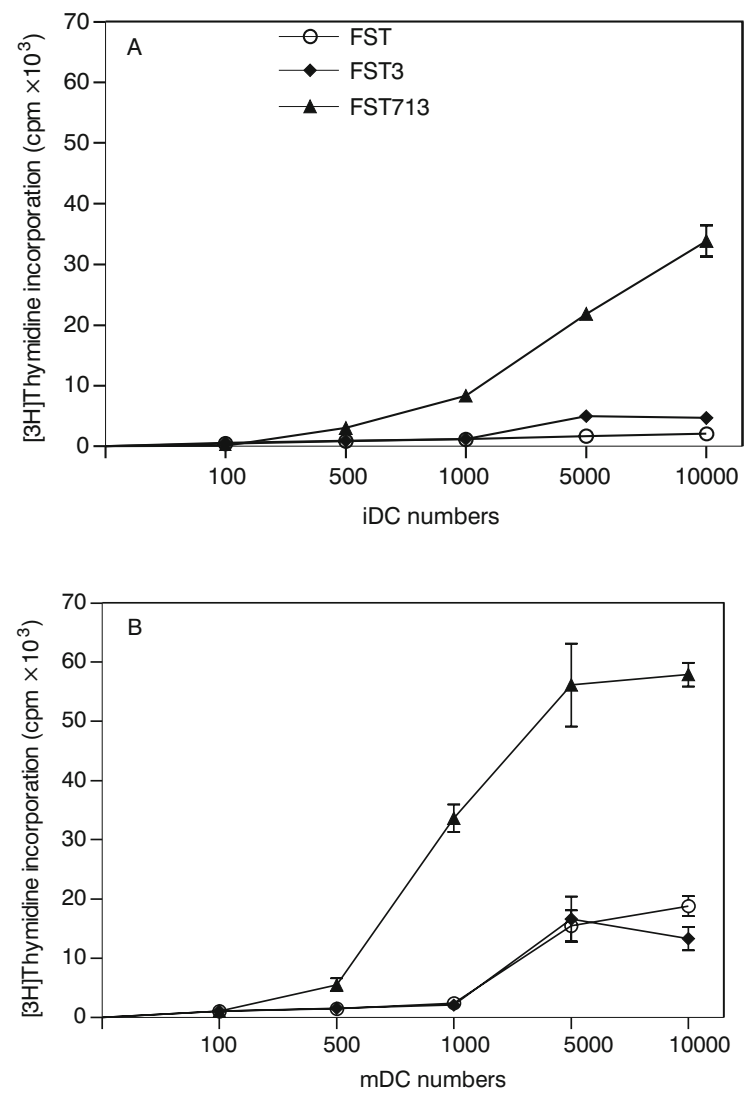

Fig. 3. The ability of DCs cultured in different media and added in various amounts to stimulate allo-MLR. Cells were cultured as described in Fig. 2. Data are expressed as $\left[{ }^{3} \mathrm{H}\right]$ Thymidine incorporation (cpm). Mean \pm SEM of results obtained in seven different experiments is shown. 


\section{Chemotactic activity and chemokine receptors}

The spontaneous migration of cells from all the media was negligible (Fig. 4). The chemotaxis of FST3-iDCs and FST713-iDCs to MIP1 $\alpha$ was comparable and significantly increased in comparison with FST-iDCs. Low chemotactic activity to MIP3 $\beta$ of the iDCs generated in all the media was observed. Maturation caused a significant decrease in the chemotaxis of FST3-mDCs and FST713-mDCs to MIP1 $\alpha$, while the migratory activity of FST-mDCs was similar to that of iDCs. The chemotaxis of all the mDCs to MIP3 $\beta$ was significantly increased, in particular that of FST713-mDCs.

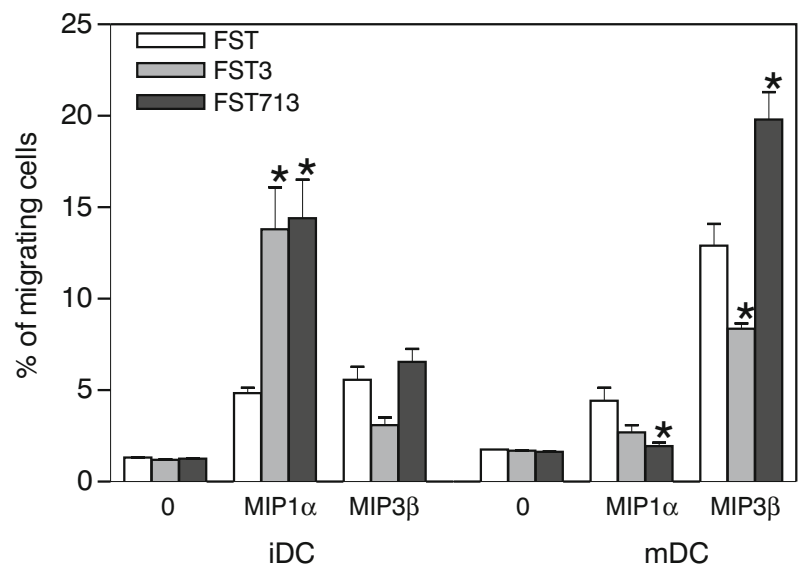

Fig. 4. Chemotaxis of iDCs and mDCs to MIP1 $\alpha$ and MIP $3 \beta$. The cells were grown in different media as indicated in Fig. 2. Mean \pm SEM of results obtained in six different experiments is shown. *Significantly increased $(\mathrm{p}<0.05)$ compared with FST medium.

The expression of CCR 1 by iDCs was seen only on FST3-iDCs (Fig. 5); CCR5 expression was absent. Surprisingly, FST713-iDCs exhibited a decreased number of $\mathrm{CCR}^{+}$(MIP3 $\beta$ receptor) cells compared with

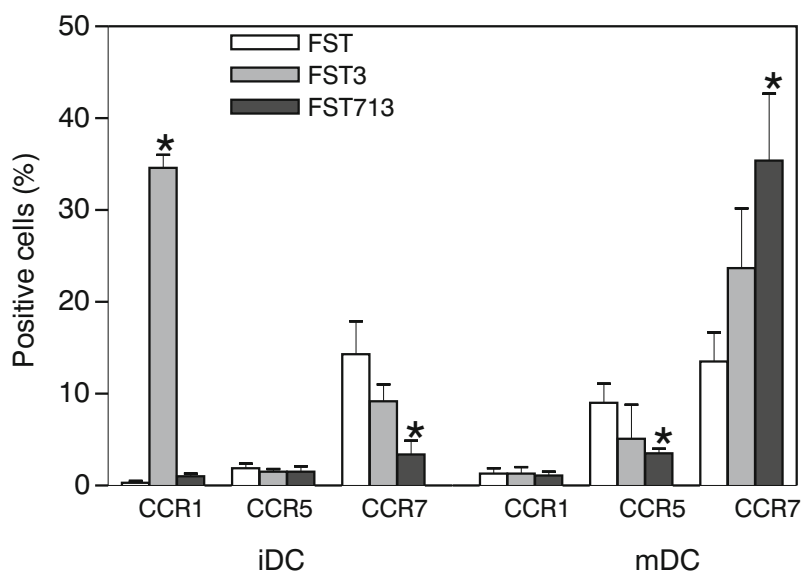

Fig. 5. The expression of chemokine receptors by iDCs and mDCs cultured in different media. Mean \pm SEM of results obtained in six different experiments is shown. *Significantly different $(\mathrm{p}<0.05)$ compared with FST medium. the others. Maturation diminished the expression of CCR1 on FST-DCs to the same low level observed on FST- and FST713-mDCs. The proportion of CCR5 ${ }^{+}$ DCs rose with maturation, although it was still below $10 \%$. The expression of CCR7 on iDCs and mDCs from FST medium was similar, in contrast to FST3-mDCs and especially to FST713-mDCs, which was significantly enhanced. Hence there was no clear relationship of CCR 1 and CCR5 expression and chemotaxis to MIP1 $\alpha$, but there was some association between enhanced expression of CCR7 on FST713-mDCs and their migration to MIP3 $\beta$.

\section{Phagocytic activity and $\mathrm{O}_{2}^{-}$production}

Engulfment of opsonized FITC-labeled $S$. aureus by FST713-iDCs was significantly lower than that of the iDCs from FST and FST3 media (Fig. 6). Also, the percentage of cells producing $\mathrm{O}_{2}^{-}$, as shown by their ability to oxidase HE, was lowest in FST713-iDCs. Maturation of cells from all media was associated with decreased phagocytic activity. The FST- and FST3-mDCs, but not FST713-mDCs, also showed a reduction in the proportion of $\mathrm{O}_{2}^{-}$-producing cells.

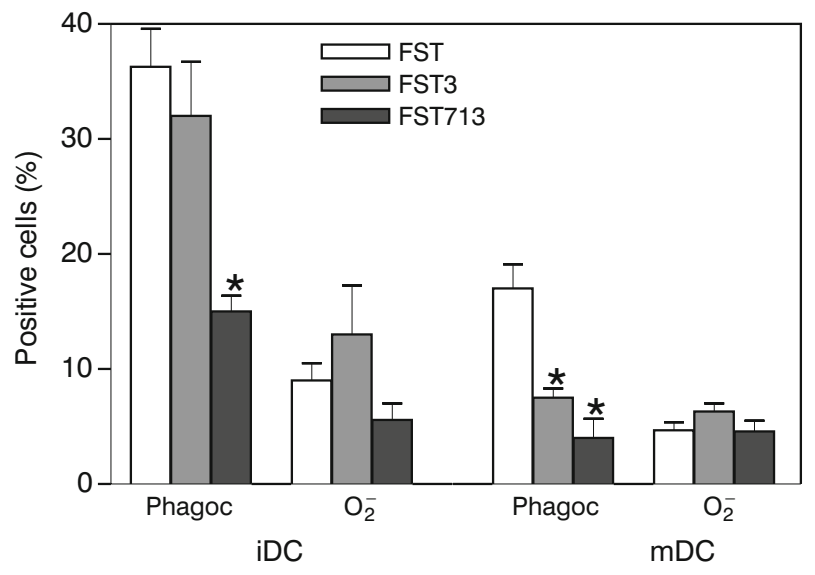

Fig. 6. Phagocytosis and $\mathrm{O}_{2}^{-}$production by iDCs and $\mathrm{mDCs}$ generated in different media. Percentages of cells that phagocytosed $S$. aureus and produced $\mathrm{O}_{2}^{-}$is shown. Mean \pm SEM of results obtained in seven different experiments is shown. *Significantly different $(\mathrm{p}<0.05)$ compared with FST and FST3 medium.

\section{DISCUSSION}

To our knowledge, only limited data concerning the effect of IL-7 and IL-13 cytokines on the generation and activity of $\mathrm{CD} 34^{+}$-derived DCs are available. The aim of the present study was to evaluate the effect of IL-7 and IL-13 used together on immunophenotype and biological activity of DCs generated from $\mathrm{CD} 34^{+}$hematopoietic progenitor cells by two-step cultures. In the first step, $\mathrm{CD} 34^{+}$cells were grown in FST medium for 7 days and then, in the second step, differentiated in FST3 or FST713 media for the next 21 days. Then part of the 
cells was further matured/differentiated by culturing in the presence of proinflammatory cytokines and $\mathrm{PGE}_{2}$. There were significant differences in the abilities of the tested media to induce the proliferation of $\mathrm{CD} 34^{+}$cells. The best with regard to yield and time of exponential growth was FST3 medium. In contrast, cells grown in FST medium containing only early-acting cytokines and in FST713 medium containing cytokines which induce DC differentiation ( $\mathrm{Li}$ et al. 2000; Morse et al. 1999) showed significantly less proliferation.

The present studies show that, compared with FST and FST3 media, the cells cultured in FST713 medium expressed higher proportions of $\mathrm{CD}_{1} \mathrm{a}^{+}, \mathrm{CD} 40^{+}$, $\mathrm{CD}^{2} 3^{+}, \mathrm{HLA}_{-} \mathrm{DR}^{+}, \mathrm{CD} 80^{+}$, and $\mathrm{CD} 86^{+}$and a lower proportion of $\mathrm{CD}_{14}{ }^{+}$cells. Similar data were obtained when DCs generated from blood monocytes in the presence of GM-SCF and IL-4 were compared with those cultured in GM-CSF and IL-7 (Li et al. 2000) or GM-CSF and IL-13 (Spisek et al. 2001). In these cases, increased expressions of the CD40, CD80, and CD86 determinants were observed. Also, Morse et al. (Morse et al. 1999) showed that DCs from IL-13-containing media exhibited higher expressions of MHC class I and II and CD86 than DCs generated in "classical" GM-CSF- and IL-4-containing medium. Our results demonstrated that FST713-iDCs showed a higher level of CD83 expression. Sato et al. (1999) also observed that IL-13-induced expression of CD83 on GM-CSF+IL-4 generated monocyte-derived DCs. This is in contrast to reports showing an absence of CD83 on monocyte-derived iDCs cultured in GM-CSF+IL-7 ( $\mathrm{Li}$ et al. 2000) or GM-CSF+IL-13 (Spisek et al. 2001). In these cases, the level of CD83 increased after maturation. The discrepancies observed may arise from different sources of cells used for differentiation and/or short-term cultures for the generation of DCs in GM-CSF-containing media. The phenotypic differences between cells grown in FST vs. FST3 vs. FST713 medium were noted in the absence of any maturation factors and were still observed after maturation. At the same time, the expression of CD33 (implicating a myeloid origin), CD40, CD11c, and CD123 on cells from all media used was similar, which in connection with the observed differences in the expression of costimulatory molecules suggested their association with the stage of maturation rather than the existence of separate subsets.

An important feature of DCs is their capacity to stimulate the proliferation of $\mathrm{T}$ lymphocytes in an allogeneic MLR. The role of IL-7 in stimulating T-cell response is underscored by observations that IL-7 maintained T-cell proliferation (Sorg et al. 1998) and that IL-7-transduced leukemic cells enhanced allo-T-cell reactivity and generated cytotoxic $\mathrm{T}$ cells against autologous leukemic blasts (Bello-Fernandez et al. 2003). In fact, FST713-iDCs showed a higher ability to stimulate MLR than cells grown in the other media. DC maturation enhanced somewhat this activity, but the cells from FST713 medium were still superior. This may indicate that they are already more mature DCs. These results are in agreement with other data showing that a higher expression of costimulatory molecules and HLA-DR, which we also observed, is connected with more efficient MLR stimulation (Ahn and Agrawal 2005).

Our results showed that the chemotaxis of FST3and FST713-iDCs to MIP1 $\alpha$ was comparable and higher than that of FST-iDCs. As MIP1 $\alpha$ is a chemoattractant for iDCs, decreased migration ability with maturation was noted, which is compatible with other studies (Lin et al. 1998). Chemotaxis to MIP3 $\beta$, a feature of mDCs, of the FST- and FST713-iDCs was higher than that of FST3-iDCs. This may indicate the presence of more mature cells grown in these media. As expected, maturation enhanced migration to MIP $3 \beta$ of the DCs from all media. The highest number of migrating cells in FST713-mDCs also indicates that they are more mature. It appears that IL-3 and a combination of IL-7 and IL-13 regulate the process of generation of DCs as shown by their different chemotactic activity. In light of the chemotactic properties, the pattern of expression of some chemokine receptors was rather unexpected. iDCs from FST3 and FST713 medium, which showed comparable chemotaxis to MIP1 $\alpha$, expressed quite different numbers of $\mathrm{CCR} 1^{+}$and a lack of $\mathrm{CCR}^{+}$cells. In contrast, cells from FST and FST3 medium showed no expression of CCR1 and CCR5, but different migratory properties. The lack of correlation between the level of chemokine receptors and chemotactic response of monocyte-derived and peripheral blood-derived DCs has already been reported. Luft et al. (Luft et al. 2002) showed that monocyte-derived DCs become migratory or proinflammatory (nonmigratory) in the presence or absence of $\mathrm{PGE}_{2}$, respectively, though both types of DCs showed similar expressions of chemokine receptors (CCR7 and CXCR4). Plasmacytoid and myeloid DCs isolated from human blood also differ in their migratory response to inflammatory chemokines, but have similar chemokine receptor expressions (Penna et al. 2001). Discrepancies between chemotactic ability and chemokine receptor levels may also suggest that other receptors, such as adenosine receptors or CD44 (Avigdor et al. 2004; Parlato et al. 2001; Schnurr et al 2004), or a different signaling pathway may be involved. However, there was an association of CCR5 expression on mDCs and migration to MIP1 $\alpha$ and CCR7 expression on FST713-mDCs and their chemotaxis to MIP3 $\beta$.

In contrast to professional phagocytes, which ingest pathogens to kill and clear them from the tissues, phagocytosis by DCs is connected with the processing of antigens and their presentation (Nagl et al. 2002). DCs show little phagocytic activity, which differs between their subsets and the level of maturation. In contrast to plasmacytoid DCs, myeloid DCs are phagocytic (Di Nicola et al. 1999). Our results indicated that FST713-iDCs exhibited less phagocytic and $\mathrm{O}_{2}^{-}$-producing capacities than DCs from other media, suggesting their more mature phenotype. The poor $\mathrm{O}_{2}^{-}$production observed here is in agreement with data of Nagl et al. (Nagl et al. 2002) and of Yu et al. (Yu et al. 1996), which 
indicated that suppression of $\mathrm{O}_{2}^{-}$generation occurs during the differentiation of monocytes to DCs. Reactive oxygen intermediates may also be involved in the signaling pathways responsible for the expression of genes and, consequently, phenotypic and functional changes. The poor response to $S$. aureus may indicate that it is connected rather with a signaling than a killing mechanisms. In fact, $\mathrm{O}_{2}{ }^{-}$and hydrogen peroxide induce maturation of DCs, as shown by the increased expressions of CD40, CD80, CD86, CD83, and HLA-DR molecules and more efficient stimulation of T-cell proliferation (Kantengwa et al. 2003; Rutault et al. 1999).

In summary, cells grown in FST, FST3, and FST713 media differ in phenotype and some biological activities. DCs cultured in FST713 are characterized by higher expressions of maturation markers (CD1a, CD83), costimulatory molecules (CD80, CD86), and HLA-DR, higher allostimulatory activity and response to MIP3 $\beta$ following maturation, and poor phagocytosis. It is concluded that FST713 medium allows the generation of a limited number of more mature DCs, while FST3 medium leads to the production of iDCs in high numbers. Hence the use of FST713 medium may be considered for the generation of mDCs for potential use in cancer immunotherapy.

Acknowledgment: This study was supported by the State Committee for Scientific Research (grant PBZ-KBN-083/P05/2002), Poland. We wish to thank Ms. Maria Woloszyn and Irena Ruggiero for skillful technical assistance.

\section{REFERENCES}

Ahn J and Agrawal B (2005) IL-4 is more effective than IL-13 for in vitro differentiation of dendritic cells from peripheral blood mononuclear cells. Int Immunol 17:1337-1346

Arrighi J F, Soulas C, Hauser C et al (2003) TNF-alpha induces the generation of Langerin/(CD207) ${ }^{+}$immature Langerhans-type dendritic cells from both $\mathrm{CD} 14^{-} \mathrm{CD} 1 \mathrm{a}^{-}$and $\mathrm{CD} 14^{+} \mathrm{CD} 1 \mathrm{a}^{-}$precursors derived from $\mathrm{CD} 34^{+}$cord blood cells. Eur J Immunol 33:2053-2063

Avigdor A, Goichberg P, Shivtiel S et al (2004) CD44 and hyaluronic acid cooperate with SDF-1 in the trafficking of human $\mathrm{CD}_{34}{ }^{+}$stem/progenitor cells to bone marrow. Blood 103:2981-2989

Banchereau J, Schuler-Thurner B, Palucka AK et al (2001) Dendritic cells as vectors for therapy. Cell 10:6271-274

Banchereau J and Steinman RM (1998) Dendritic cells and the control of immunity. Nature 392:245-252

Bello-Fernandez C, Stasakova J, Renner A et al (2003) Retrovirus-mediated IL-7 expression in leukemic dendritic cells generated from primary acute myelogenous leukemias enhances their functional properties. Blood 101:2184-2190

Bontkes HJ, de Gruijl TD, Schuurhuis GJ et al (2002) Expansion of dendritic cell precursors from human CD34 ${ }^{+}$ progenitor cells isolated from healthy donor blood; growth factor combination determines proliferation rate and functional outcome. J Leukoc Biol 72:321-329
Dalgaard J, Beckstrom KJ, Jahnsen FL et al (2005) Differential capability for phagocytosis of apoptotic and necrotic leukemia cells by human peripheral blood dendritic cell subsets. J Leukoc Biol 77:689-698

Di Nicola M, Longoni P, Magni M et al (1999) The influence of interleukin (IL)-4 and IL-13 on human dendritic cell differentiation from $\mathrm{CD}_{3}{ }^{+}$progenitor cells: the importance of the source of serum. Exp Hematol 27:386-388

Kantengwa S, Jornot L, Devenoges C et al (2003) Superoxide anions induce the maturation of human dendritic cells. Am J Respir Crit Care Med 167:431-437

Li LQ, Masucci MG, Levitsky V (2000) Effect of interleukin-7 on the in vitro development and maturation of monocyte derived human dendritic cells. Scand J Immunol 51:361-367

Lin CL, Suri RM, Rahdon RA et al (1998) Dendritic cell chemotaxis and transendothelial migration are induced by distinct chemokines and are regulated on maturation. Eur J Immunol 28:4114-4122

Liu Y-J (2001) Dendritic cell subsets and lineages, and their functions in innate and adoptive immunity. Cell 106:259-262

Luft T, Jefford M, Luetjens P et al (2002) Functionally distinct dendritic cell (DC) populations induced by physiologic stimuli: prostaglandin $E(2)$ regulates the migratory capacity of specific DC subsets. Blood 100:1362-1372

Morse MA, Lyerly HK, Li Y (1999) The role of IL-13 in the generation of dendritic cells in vitro. J Immunother 22:506-513

Nagl M, Kacani L, Mullauer B et al (2002) Phagocytosis and killing of bacteria by professional phagocytes and dendritic cells. Clin Diagn Lab Immunol 9:1165-1168.

Parlato S, Santini SM, Lapenta C et al (2001): Expression of CCR-7, MIP-3beta, and Th-1 chemokines in type I IFN-induced monocyte-derived dendritic cells: importance for the rapid acquisition of potent migratory and functional activities. Blood 98:3022-3029

Penna G, Sozzani S, Adorini L (2001) Cutting edge: Selective usage of chemokine receptors by plasmacytoid dendritic cells. J Immunol 167:1862-1866.

Piemonti L, Bernasconi S, Luini W et al (1995) IL-13 supports differentiation of dendritic cells from circulating precursors in concert with GM-CSF. Eur Cytokine Netw 6:245-252

Romani N, Reider D, Heuer M et al (1996) Generation of mature dendritic cells from human blood. An improved method with special regard to clinical applicability. J Immunol Methods 196:137-151

Rosenzwajg M, Camus S, Giugon M et al (1998) The influence of interleukin (IL)-4, IL-13, and Flt3 ligand on human dendritic cell differentiation from cord blood CD $34^{+}$progenitor cells. Exp Hematol 26:63-72

Rutault K, Alderman C, Chain BM et al (1999) Reactive oxygen species activate human peripheral blood dendritic cells. Free Rad Biol Med 26:232-238

Sallusto F and Lanzavecchia A (1994) Efficient presentation of soluble antigen by cultured human dendritic cells is maintained by granulocyte/macrophage colony-stimulating factor plus interleukin 4 and downregulated by tumor necrosis factor alpha. J Exp Med 179:1109-1118 
Sato K, Nagayama H, Tadokoro K et al (1999) Interleukin-13 is involved in functional maturation of human peripheral blood monocyte-derived dendritic cells. Exp Hematol 27:326-336.

Schnurr M, Toy T, Shin A et al (2004) Role of adenosine receptors in regulating chemotaxis and cytokine production of plasmacytoid dendritic cells. Blood 103:1391-1397

Sorg RV, McLellan AD, Hock BD et al (1998) Human dendritic cells express functional interleukin-7. Immunobiology 198:514-526

Spisek R, Bretaudeau L, Barbieux I et al (2001) Standardized generation of fully mature p70 IL-12 secreting monocyte-derived dendritic cells for clinical use. Cancer Immunol Immunother 50:417-427
Takahashi K, Honeyman MC, Harrison LC (1997) Dendritic cells generated from human blood in granulocyte macrophage-colony stimulating factor and interleukin-7. Hum Immunol 55:103-116

Węglarczyk K, Baran J, Zembala M et al (2004) Caspase-8 activation precedes alterations of mitochondrial membrane potential during monocyte apoptosis induced by phagocytosis and killing of Staphylococcus aureus. Infect Immun 72:2590-2597

Yu D, Imajoh-Ohmi S, Akagawa K, Kanegasaki S (1996) Suppression of superoxide-generating ability during differentiation of monocytes to dendritic cells. J Biochem 119:23-28

Zou GM, Tam YK (2002) Cytokines in the generation and maturation of dendritic cells: recent advances. Eur Cytokine Netw 13:186-199 